\title{
Rare Association Between an Endometrioma and A Mature Cystic Teratoma on the Same Ovary in A Postmenopausal Woman: A Case Report and Review of Literature
}

\author{
Balint 0*, Secoșan C, Pirtea L and Grigoraș D \\ Department Obstetrics and Gynecology, University of Medicine and Pharmacy 'Victor Babeș' Timisoara, Romania
}

Submission: January 11, 2020; Published: January 20, 2020

*Corresponding author: Balint O, Department Obstetrics and Gynecology, University of Medicine and Pharmacy 'Victor Babeș' Timisoara, Romania

\section{Abstract}

In spite of their increased individual incidence, association of cystic teratomas and ovarian endometriomas on the same ovary is extremely rare. Moreover, both types of ovarian tumors are considered conditions affecting mostly premenopausal women. We present a case of a postmenopausal woman presenting with a symptomatic right ovarian mass. Ultrasound appearance consisted in a bilocular mass with a component suggestive for an endometrioma and the other of a complex cyst with papillary projections. The histopathology report revealed the co-existence of an endometrioma with a mature cystic teratoma. Currently this is the only case report of this association of ovarian tumor types in a postmenopausal woman.

Keywords: Endometrioma; Dermoid cyst; Mature teratoma

Case Report



Figure 1: (A) Ultrasound image of a bilocular ovarian mass composed of a lower cyst with "ground glass" content and an upper complex cyst with fluid and solid components. (B) Papillary projection originating from the upper cyst wall. (C) Intraoperative image of the ovarian mass.
A 59 years old postmenopausal woman presented in our service with a 3 months history of moderate non-colicky lower abdominal pain and recurrent minimal abnormal vaginal bleeding. The patient had normal BMI and no significant medical or surgical history. At the admission, pelvic examination revealed minimal bleeding through the external cervical os, a normal sized uterus and a tender voluminous mass occupying the right iliac fossa. A transvaginal ultrasound showed an anteverted uterus with a normal myometrial echotexture and an endometrial thickness of $8 \mathrm{~mm}$. On the right side of the uterus a bilocular $8.9 / 7.6 \mathrm{~cm}$ cystic ovarian mass was observed. The bilocular structure was composed of a lower cyst with a homogenous, hypoechoic "ground glass" like content, highly suggestive for an endometrioma, separated by a thick septum from an upper cyst with heterogenous content, with solid projections originating from the cyst wall (Figure 1). No internal vascularization was noticed on colour Doppler. The left ovary showed a normal appearance for a postmenopausal status. No other abnormal findings were observed. In order to investigate her abnormal uterine bleeding an endometrial biopsy was obtained through D\&C. The histopathology showed a complex endometrial hyperplasia with atypia. 
For the surgical treatment, a laparoscopic approach was chosen. Intraoperative findings revealed a normally appearance uterus and left adnexa and a right voluminous ovarian mass with no extracystic vegetation. (Figure 1) A total hysterectomy with bilateral adnexectomy was performed. The uterus and left adnexa were extracted from the abdomen through the vagina followed by the intact ovarian mass placed in an endobag.

Post-postoperative gross examination of the ovarian mass revealed the bilocular structure seen by ultrasound. The dissection of the lower cyst showed a chocolate-like content confirming the diagnosis of endometrioma suggested pre-operatively. The upper cyst was also dissected, and its content consisted in strands of hair and fatty tissue suggesting a diagnosis of mature teratoma (dermoid cyst). The histopathology examination confirmed the ovarian mass as being an association between an endometrioma and a mature cystic teratoma. No other pathological changes were observed regarding the uterus besides the already known endometrial hyperplasia. The patient recovered well and was discharged 48 hours later.

\section{Discussion}

Mature cystic teratomas and ovarian endometriomas represent common ovarian benign masses. Teratomas are the most frequent germ cell tumors of the ovary with an incidence of $20 \%$ of all ovarian masses while endometriomas are present in $17-44 \%$ of women with endometriosis $[1,2]$. Also, both types of ovarian masses are considered conditions of premenopausal women with only few cases reported after menopause. In spite of their increased individual incidence, association of cystic teratomas and ovarian endometriomas on the same ovary is extremely rare. Our literature search identified 6 cases reported from 1960 until present (June 2019). The first case reported is an incidental finding in a 23 years old patient during surgery for a ovarian mass [3]. Later, Caruso and Pirelli describes a case of a 28 years old woman with bilateral ovarian masses with a histology report revealing separate endometrial and teratomatous lesions on her left ovary [4]. In recent literature, four cases are reported. Van der Merwe presents the case of a 30 years old patient with a voluminous compressive ovarian mass ( $43 \times 23 \times 20 \mathrm{~cm})$ of unknown origin at the time of surgery. Histologic examination showed 3 types of lesion clearly separated, a mature cystic teratoma, a mucinous cystadenoma and areas of endometrial stroma. This case presents the largest mass reported, involving this co-existence of pathologies and also the only one with the association of a third lesion [5]. The last three cases also report young women, ages 28 to 35 years old, with a unilateral ovarian mass with dimensions ranging between 6 and $8 \mathrm{~cm}$ in largest diameter. Two of the cases were diagnosed due to the appearance of a second condition, adnexal torsion and ectopic pregnancy (on the contralateral side), respectively [6,7]. The third case was an incidental finding [8]. All 3 patients were treated by laparoscopic approach.

Our case is currently the only reported case involving the co-existence of an endometrioma and a mature teratoma in a postmenopausal woman. Postmenopausal endometriosis is a poorly studied subject in medical literature. In one of the largest studies, 72 cases of postmenopausal endometriosis were identified over a 12 years period. Among these patients, cystic ovarian endometriosis was the most frequent form representing $79.2 \%$. The median age was 58.5 years [9]. Although the exact mechanism that cause the appearance of endometriosis after menopause is unknown, several theories have been described, most accepted being the production of estrogen from non-ovarian sources like adrenal gland or adipose tissue or reactivation of old endometriotic lesion during hormone replacement therapies $[10,11]$. On the other hand, the incidence of mature cystic teratomas in postmenopausal woman is about $10 \%$ [12]. In this group of women the natural evolution of mature teratomas involves slow growth but higher malignant transformation rates as opposed to premenopausal women $[13,14]$.

Pre-operative diagnosis of postmenopausal ovarian masses represents a challenge due to the different presentation and significance of ovarian cysts. Transvaginal ultrasound remains the most effective way of evaluating these patients. Is it important to be aware that some of the sonographic characteristics of different type of ovarian cysts/masses change with age. The main sign of endometriotic cysts, represented by the "ground glass" echogenicity is present in only $62 \%$ of women over 45 years but with a rate of papillary projections of $14 \%$ while in younger women, the "ground glass" echogenicity can be observed in $77 \%$ of case with only $3 \%$ presenting papillary projections [15].

Similar with the last 3 cases, involving masses of under $8 \mathrm{~cm}$ diameter, our case was treated by laparoscopic approach and the mass was extracted using an endobag to prevent spillage. Current case highlights the importance of thorough evaluation of postmenopausal ovarian masses. The possibility of co-existence of different ovarian lesions increases the challenge imposed by the discovery of an ovarian mass and must be take into consideration even in a menopausal woman. No diagnosis cannot be excluded based on patient age.

\section{References}

1. Del Carpio-Orantes L (2013) Virosis emergentes en México. Revista Médica del Instituto Mexicano del Seguro Social 51(1): 8-11.

2. Del Carpio-Orantes L (2016) Zika, a neurotropic virus? Revista médica del Instituto Mexicano del Seguro Social 54(4): 540-543.

3. Del Carpio-Orantes L (2018) Vías de transmisión del Zika, se puede transmitir de persona a persona? Rev Med Inst Mex Seguro Soc 56(4): 410-413. 
4. Del Carpio-Orantes L, González Clemente MC (2018) Zika, enfermedad afebril? Rev Med Inst Mex Seguro Soc 56(3): 305-308.

5. Del Carpio-Orantes L, María del Carmen González-Clemente, Teresa Lamothe-Aguilar (2018) Zika and its vector mosquitoes in Mexico. Journal of Asia-Pacific Biodiversity 11(2): 317-319.

6. Del Carpio-Orantes L (2019) Culex and Aedes Vexans, confirmed vectors of zika in Mexico. Med Int Méx 35(6): 931-933.

7. Del Carpio-Orantes L (2018) Congenital Zika syndrome, time to communicate experiences. J Matern Fetal Neonatal Med 32(20): 35093510 .
8. Pan American Health Organization (2017) World Health Organization. Zika suspected and confirmed cases reported by countries and territories in the Americas Cumulative cases, 2015-2017.

9. https://www.gob.mx/cms/uploads/attachment/file/522438/ Cuadro_Casos_ZIKA_y_Emb_sem_52_2019

10. https://www.gob.mx/cms/uploads/attachment/file/454004/ Cuadro_Sx_Congenito_asociado_a_Zika_15042019

11. Del Carpio-Orantes L, González Clemente MC (2018) Microcefalia y arbovirus. Rev Med Inst Mex Seguro Soc 56(2): 186-188.

\section{Your next submission with Juniper Publishers will reach you the below assets}

- Quality Editorial service

- Swift Peer Review

- Reprints availability

- E-prints Service

- Manuscript Podcast for convenient understanding

- Global attainment for your research

- Manuscript accessibility in different formats

( Pdf, E-pub, Full Tsext, Audio)

- Unceasing customer service

Track the below URL for one-step submission https://juniperpublishers.com/online-submission.php 